\title{
DESCOLORAÇÃO E DEGRADAÇÃO DE POLUENTES ORGÂNICOS EM SOLUÇÕES AQUOSAS ATRAVÉS DO PROCESSO FOTOELETROQUÍMICO
}

\author{
Rodnei Bertazzoli* e Ronaldo Pelegrini
}

Departamento de Engenharia de Materiais, Faculdade de Engenharia Mecânica, Universidade Estadual de Campinas, CP 6122, 13083-970 Campinas - SP

Recebido em 25/6/01; aceito em 10/10/01

PHOTOELECTROCHEMICAL DISCOLORATION AND DEGRADATION OF ORGANIC POLLUTANTS IN AQUEOUS SOLUTIONS. Organic compounds responsible for the color of wastewaters are usually refractory to biological digestion. In this paper the photo-assisted electrolysis process is used for color removal from three of the most colored wastewaters, which are daily generated in large amounts: the E1 bleach Kraft mill effluent, a textile reactive dye effluent and a landfill leachate. Electrolysis was carried out at $26,5 \mathrm{~mA} \mathrm{~cm}$ in a flow reactor in which the anode surface was illuminated by a $400 \mathrm{~W}$ high pressure $\mathrm{Hg}$ bulb. In all experiments $70-75 \%$ of color reduction was observed which was also followed by a net organic load oxidation.

Keywords: electrochemical treatment of effluents; photoelectrochemical treatment; kraft mill effluent; textile dyes effluent; landfill leachate.

\section{INTRODUÇÃO}

Os tratamentos de efluentes aquosos industriais, baseados em processos biológicos de degradação, são os mais utilizados para a oxidação de poluentes orgânicos. Isso se deve a características como baixo custo e possibilidade de tratar grandes volumes. Entretanto, a capacidade de certos microrganismos para degradar alguns compostos orgânicos é limitada ${ }^{1,2}$. Além disso, variações de $\mathrm{pH}$, ou da concentração de poluentes podem inibir ou paralisar o metabolismo. Pequenas diferenças na estrutura de um composto poluente ou na composição do meio também podem atrapalhar o funcionamento de um sistema biológico estabelecido. Devido a esse conjunto de fatores, um consórcio de microorganismos pode não mais reconhecer certas substâncias e não degradá-las, ou transformá-las em produtos mais tóxicos ${ }^{3}$.

Compostos organoclorados, principalmente fenólicos, tendem a ser resistentes à degradação biológica ${ }^{4}$. Paralelamente, a coloração de efluentes aquosos é outra forte limitação para os tratamentos biológicos. A cor não tem sido regulamentada, principalmente devido à crença de que compostos que contêm grupos cromóforos não apresentem um apreciável impacto ambiental ${ }^{5}$. No entanto, a cor pode ser altamente interferente nos processos fotossintéticos naturais nos leitos dos rios e em lagoas, provocando alterações na biota aquática principalmente nas imediações da descarga ${ }^{6-9}$. Os tratamentos biológicos convencionais são pouco eficientes na remoção de cor e, em muitos casos, o efluente tratado pode apresentar uma coloração mais acentuada ${ }^{4}$.

Neste sentido, a tecnologia eletroquímica pode ser uma forma eficiente e versátil de controle da poluição aquosa, modificando, degradando ou mineralizando compostos orgânicos através de processos onde o único reagente envolvido é o elétron. A oxidação anódica pode ocorrer por troca direta de elétrons entre o composto orgânico e a superfície do eletrodo ou, de forma indireta, pela intermediação de espécies eletroativas oxidantes formadas no anodo ${ }^{10-17}$. Quando a eletrólise é conduzida a potenciais tais que a evolução de oxigênio ocorra de forma simultânea, a oxidação indireta parece ser o principal processo de transferência de átomos de oxigênio para o material a ser oxidado ${ }^{16}$. Esse processo eletroquímico de oxidação anódica envolve a formação de radicais hidroxila $\left(\mathrm{OH}^{*}\right)$, espécie intermediária da reação de evolução de oxigênio, que adsorve fisicamente na superfície do eletrodo. Na superfície de anodos revestidos com óxidos metálicos $\left(\mathrm{MO}_{\mathrm{x}}\right)$, do tipo dimensionalmente estáveis (ADE), estes sítios ativos oxidantes podem se transformar em óxidos superiores, quimicamente adsorvidos, do tipo $\mathrm{MO}_{\mathrm{x}+1}$. Ambas as espécies são responsáveis pela oxidação de compostos orgânicos ${ }^{10-19}$.

O uso dos eletrodos de óxido, tipo ADE, na oxidação eletroquímica de orgânicos permite ainda que a eletrólise possa ser assistida pela fotocatálise heterogênea quando a superfície do eletrodo apresenta fotoatividade ${ }^{20-22}$. O processo eletroquímico foto-assistido, também chamado de fotoeletroquímico ${ }^{21-23}$, consiste na percolação da solução a ser tratada através de um reator eletrolítico onde o anodo, revestido com óxidos metálicos, permanece sob a incidência da radiação UV. Essa combinação de processos tem mostrado um efeito sinérgico, onde as velocidades de degradação observadas são até uma ordem de grandeza maior, quando comparadas com a soma daquelas resultantes da aplicação dos processos individuais ${ }^{22}$.

Este trabalho mostra os resultados da aplicação do processo fotoeletroquímico, já em escala piloto, no tratamento de soluções que se caracterizam pela alta concentração de espécies poluentes e forte coloração. Foram selecionados, para aplicação do processo fotoeletroquímico, os descartes aquosos gerados nas indústrias têxtil e de papel e celulose, além do efluente aquoso proveniente de aterros sanitários municipais. Este último, conhecido como chorume de lixo, é um potencial poluente do lençol freático e aquiíferos próximos.

\section{MECANISMO FOTOELETROQUÍMICO DE OXIDAÇÃO}

A Figura 1 (A) apresenta, de forma esquemática, as possíveis reações envolvidas na formação de radicais hidroxila no processo fotoeletroquímico, onde a discussão é restrita ao meio ácido. $\mathrm{Na}$ eletrólise, a descarga das moléculas de água na superfície do anodo de óxido metálico, $\mathrm{MO}_{\mathrm{x}}$, forma radicais hidroxila fisicamente adsorvidos, de acordo com a equação (a):

$\mathrm{MO}_{\mathrm{x}}+\mathrm{H}_{2} \mathrm{O} \rightarrow \mathrm{MO}_{\mathrm{x}}\left(\mathrm{OH}^{*}\right)+\mathrm{H}^{+}+\mathrm{e}^{-}$ 
(A)

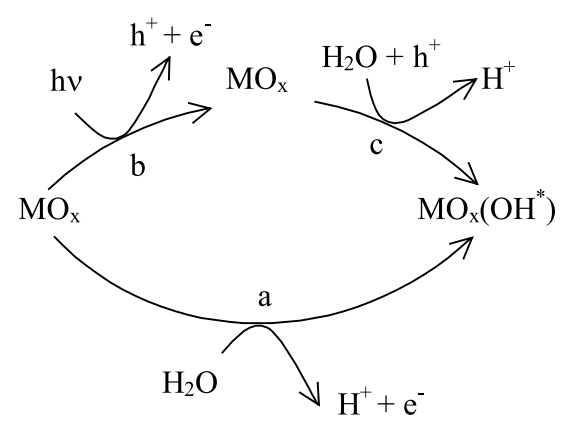

(B)

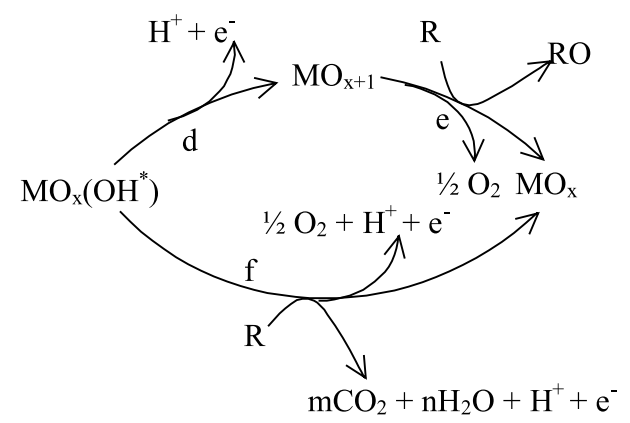

Figura 1. (A) Mecanismo de formação do radical hidroxila na superfície de anodos dimensionalmente estáveis: via descarga anódica da água (reação a); via descarga fotoeletroquímica da água (reações b-c); (B) Mecanismo de oxidação de orgânicos pelo radical hidroxila: via formação de óxidos superiores (reações d-e); via combustão direta (reação f). Adaptada da Ref. 17

Paralelamente, a incidência de radiação com energia hv, sobre o revestimento de óxido, promove elétrons para a banda de condução, propiciando a separação de cargas conforme a reação (b):

$\mathrm{MO}_{\mathrm{x}} \stackrel{\mathrm{h} \nu}{\rightarrow} \mathrm{MO}_{\mathrm{x}}+\mathrm{h}^{+}+\mathrm{e}^{-}$

onde $\mathrm{h}^{+}$representa uma lacuna que possibilita a descarga anódica da água, de acordo com o processo (c):

$\mathrm{MO}_{\mathrm{x}}+\mathrm{H}_{2} \mathrm{O}+\mathrm{h}^{+} \rightarrow \mathrm{MO}_{\mathrm{x}}\left(\mathrm{OH}^{*}\right)+\mathrm{H}^{+}$

As reações (a) e (c) mostram que, no processo fotoeletroquímico, a formação de radicais hidroxila ocorre de forma aditiva, o que explica as altas velocidades de degradação da matéria orgânica.

A partir da formação dos radicais hidroxila, a oxidação ocorre através dos mecanismos discutidos na literatura ${ }^{17}$, onde duas rotas são possíveis: combustão direta e oxidação gradativa. A Figura 1 (B) mostra que os radicais hidroxila podem oxidar diretamente os compostos orgânicos $(\mathrm{R})$ :

$\mathrm{MO}_{\mathrm{x}}\left(\mathrm{OH}^{*}\right)+\mathrm{R} \rightarrow \mathrm{MO}_{\mathrm{x}+1}+\mathrm{mCO}_{2}+\mathrm{nH}_{2} \mathrm{O}+\mathrm{H}^{+}+\mathrm{e}^{-}$

ou transformar-se em óxidos superiores que promovem a oxidação gradativa:

$\mathrm{MO}_{\mathrm{x}}\left(\mathrm{OH}^{*}\right) \rightarrow \mathrm{MO}_{\mathrm{x}+1}+\mathrm{H}^{+}+\mathrm{e}^{-}$

$\mathrm{MO}_{\mathrm{x}+1}+\mathrm{R} \rightarrow \mathrm{MO}_{\mathrm{x}}+\mathrm{RO}$

Conforme a figura 1(B), a evolução de oxigênio concorre com os processos (e) e (f).
Os resultados que serão apresentados nesse artigo foram obtidos com um eletrodo revestido com uma mistura de óxidos de rutênio e de titânio. Embora a fase mais fotoativa do dióxido de titânio seja a anatase ${ }^{24}$, devido ao processo térmico envolvido na preparação dos eletrodos ADE, o dióxido de titânio apresenta-se na fase rutílica ${ }^{21}$, que possui uma diferença de energia entre as bandas de valência e de condução maior que aquela observada para a fase anatase. No entanto, o dióxido de rutênio presente na composição do óxido parece desempenhar o papel de sorvedouro de elétrons, evitando a recombinação elétron/lacuna, além de reduzir a diferença de energia entre as bandas de valência e de condução.

\section{CARACTERIZAÇÃO DAS SOLUÇÕES AQUOSAS}

\section{Efluente da indústria de papel e celulose}

A indústria de papel e celulose representa uma das atividades que emprega grandes volumes de água e libera uma descarga altamente tóxica ${ }^{25}$. Diariamente, estima-se que são liberados mais de 62 milhões de metros cúbicos de efluentes produzidos na polpação e branqueamento da celulose por estas indústrias distribuídas ao redor do planeta $^{26}$.

Para a produção do papel é necessário separar a lignina da celulose na polpa da madeira. A lignina é uma macromolécula aromática tridimensional, de estrutura não uniforme, e a sua eliminação se dá por oxidação, que a fragmenta em diversas moléculas de diferentes tamanhos, muitas das quais apresentando maior toxicidade ${ }^{27}$.

O processamento mais empregado para separar a lignina da celulose é o processo Kraft que remove aproximadamente $90 \%$ dessa macromolécula até a formação da polpa escura. Os fragmentos da lignina nesta fase são eliminados através do licor negro, geralmente aproveitado como combustível. Os $10 \%$ restantes têm que ser eliminados nos processos de branqueamento, que normalmente são realizados com cloro, hidróxido de sódio e peróxido de hidrogênio, conforme os estágios de branqueamento empregados. Quando a sua eliminação é feita por cloração, é comum a presença de diversas estruturas clorofenólicas nos efluentes derivados dos estágios de branqueamento da celulose ${ }^{4}$. No estágio de branqueamento, denominado de primeira extração alcalina (E1), são eliminadas altas concentrações de fragmentos de lignina com alta massa molecular ${ }^{27-29}$. Os compostos poluentes encontrados no efluente E1, como fenóis, clorofenóis e cloroligninas, apresentam elevada toxicidade e mutagenicidade, sendo os mais resistentes à oxidação nos processos de tratamentos biológicos convencionais ${ }^{30}$.

No caso da indústria papeleira da região de Campinas- SP, onde foram coletadas as amostras para tratamento, são produzidos em média $250 \mathrm{~m}^{3} / \mathrm{h}$ do efluente E1. A Tabela 1 apresenta os principais parâmetros físico-químicos do efluente da indústria papeleira, ca-

Tabela 1. Parâmetros físico-químicos do efluente E1*

\begin{tabular}{lc}
\hline Absorbância (em $465 \mathrm{~nm})$ & 0,71 \\
$\mathrm{pH}$ & 11,0 \\
Carbono orgânico total $\left(\mathrm{mg} \mathrm{L}^{-1}\right)$ & 1275 \\
Fenóis totais $\left(\mathrm{mg} \mathrm{L}^{-1}\right)$ & 37 \\
Toxicidade aguda- Daphnia similis (\% de inibição) & 55 \\
OXA (mg L-1) & 60 \\
DQO (mg L-1) & 2500 \\
DBO (mg L-1) & 760 \\
Condutividade a $30{ }^{\circ} \mathrm{C}(\mathrm{mS})$ & 10,1
\end{tabular}

* efluente gerado na primeira extração alcalina do estágio de branqueamento da celulose nas indústrias papeleiras. 
racterizado pela forte coloração (medida como absorbância em 465 $\mathrm{nm}$ ) e alta concentração de poluentes orgânicos, evidenciada pelos valores de carbono orgânico total (COT) e de demandas química (DQO) e bioquímica (DBO) de oxigênio. Os organoclorados foram medidos como organohalogenados absorvíveis (OXA).

\section{Efluente simulado da indústria têxtil}

A indústria têxtil é outra atividade que tem sido considerada de alto impacto ao meio ambiente, principalmente devido à produção de grandes volumes de rejeitos contendo altas cargas de compostos orgânicos e efluentes fortemente coloridos ${ }^{6,7}$.

Devido à sua própria natureza, os corantes são detectáveis pelo olho humano, mesmo em concentrações de $1 \mathrm{mg}$. $\mathrm{L}^{-131}$. No caso dos corantes reativos a concentração detectada é ainda menor, em torno de $5 \mu \mathrm{g}$. $\mathrm{L}^{-132}$.

A maior parte dos efluentes da indústria têxtil é oriunda das etapas de tingimento. Esses corantes, quando não são resistentes aos tratamentos biológicos, apresentam uma cinética lenta de degradação. Os corantes reativos são muito usados pela sua propriedade de ligarem-se às fibras têxteis por meio de ligações covalentes ${ }^{20}$. Porém, sua proporção de fixação nos tecidos é variável, por volta de 60 a $90 \%$, razão pela qual, quantidades substanciais são descartadas nos efluentes aquosos ${ }^{33}$. No caso particular do corante Azul Reativo 19 (Azul QR), a baixa proporção de fixação (75-80\%) é devido à competição entre a forma reativa (vinil sulfonato) e as formas hidrolisadas, que não se fixam às fibras ${ }^{20}$. No restante, o efluente da indústria têxtil apresenta alta concentração de amido, facilmente biodegradável. Por essa razão, o efluente usado neste trabalho foi simulado, tendo sido preparado a partir de $15 \mathrm{mg} . \mathrm{L}^{-1}$ do corante em um eletrólito suporte de sulfato de sódio, com as características apresentadas na Tabela 2.

Tabela 2. Características do efluente têxtil sintético (solução do corante Azul QR)

\begin{tabular}{lccc}
\hline Corante & Concentração & $\begin{array}{c}\text { Absorbância } \\
(\text { em 600 nm) }\end{array}$ & $\mathrm{pH}$ \\
\hline Azul QR & $15 \mathrm{mg} . \mathrm{L}^{-1}$ & 0,150 & 7,0 \\
\hline
\end{tabular}

\section{Efluente de aterros sanitários (chorume de lixo doméstico)}

O chorume é um líquido negro, odor nauseante, que pode ser definido como um líquido com altas concentrações de compostos orgânicos e inorgânicos, resultado da percolação da água através dos resíduos domésticos, dispostos em aterros sanitários, em processo de decomposição. A composição físico-química do chorume é extremamente variável dependendo de fatores que vão desde as condições pluviométricas locais, tempo de disposição e das características do próprio lixo.

O chorume pode conter altas concentrações de sólidos suspensos, metais pesados e compostos orgânicos originados da degradação de substâncias que são metabolizadas como carboidratos, proteínas e gorduras. Por apresentar substâncias altamente solúveis, o chorume pode contaminar as águas do subsolo nas proximidades do aterro sanitário.

A Tabela 3 apresenta as características físico-químicas do chorume de lixo, coletado em um dos aterros sanitários municipais da cidade de Campinas. A produção do chorume varia com as estações do ano. Nos meses de maior precipitação de chuvas, o aterro produz mais chorume e menos gás combustível, resultante do processo fermentativo. No período de coleta da amostra (agosto de 2000), época de poucas chuvas, o aterro produzia $10 \mathrm{~m}^{3} \cdot \mathrm{h}^{-1}$ de chorume,
Tabela 3. Características do chorume de lixo doméstico

\begin{tabular}{lc}
\hline Absorbância (em $350 \mathrm{~nm})$, & 0,515 \\
após diluir 15 X & \\
pH & 8,0 \\
DQO $\left(\mathrm{mg} \mathrm{L}^{-1}\right)$ & 12000 \\
DBO $\left(\mathrm{mg} \mathrm{L}^{-1}\right)$ & 7500 \\
COT $\left(\mathrm{mg} \mathrm{L}^{-1}\right)$ & 3050 \\
Metais Detectados & $\mathrm{Cu}, \mathrm{Ni}, \mathrm{Fe}, \mathrm{Pb}, \mathrm{Mn}, \mathrm{Cd}, \mathrm{Zn}, \mathrm{Na}, \mathrm{K}, \mathrm{Cr}$ \\
\hline
\end{tabular}

permanecendo estocado em lagoas com fundo impermeabilizado sem receber qualquer tratamento.

\section{PROCEDIMENTO EXPERIMENTAL}

O reator para o tratamento fotoeletroquímico, que pode ser observado na Figura 2, foi construído para processar 20 litros de efluente em sistema de recirculação. Possui uma bomba hidráulica e um rotâmetro para o controle da vazão. O processo de tratamento ocorre no tanque inferior, onde se localizam os eletrodos. O tanque superior é auxiliar para a recirculação da solução. A Figura 3 mostra os

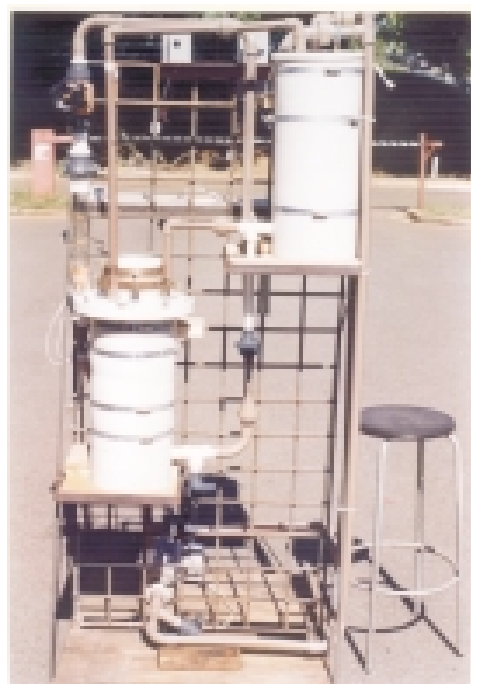

Figura 2. Foto do reator para tratamento de descartes aquosos pelo processo fotoeletroquímico

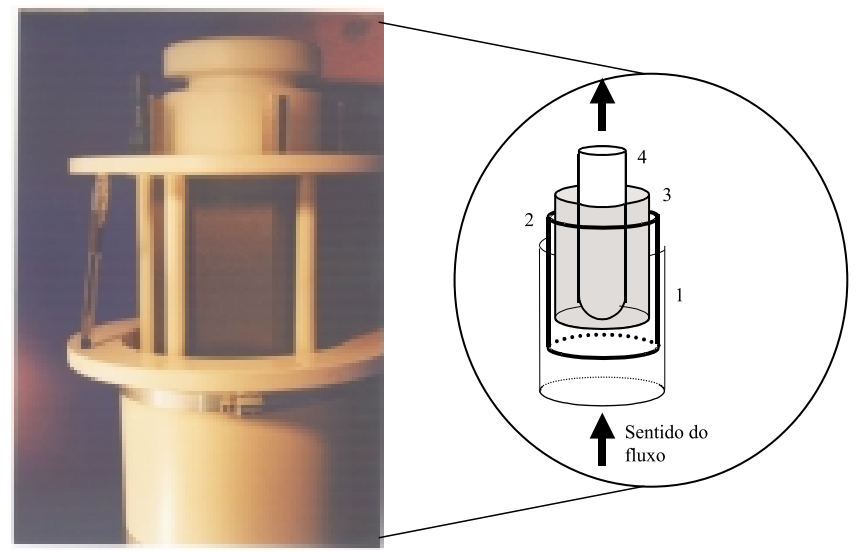

Figura 3. Vista da câmara de eletrodos onde ocorre a oxidação dos poluentes orgânicos. Detalhe: 1) Estrutura externa em PVC; 2) Anodo cilíndrico de Ti/70TiO $/ 30 \mathrm{RuO}_{2}$; 3) Catodo de titânio expandido; 4) Poço da lâmpada 
detalhes do sistema de eletrodos com um tubo de quartzo no centro como alojamento para a lâmpada. Em volta da lâmpada, de forma concêntrica, localiza-se o conjunto anodo/catodo. O anodo é de titânio revestido com óxidos na proporção de $70 \mathrm{TiO}_{2} / 30 \mathrm{RuO}$, fornecido pela De Nora do Brasil, com área $1500 \mathrm{~cm}^{2}$. O catodo é uma tela de titânio expandida. A distância anodo/catodo é de $2 \mathrm{~mm}$ e a solução entra em fluxo ascendente através de um promotor de turbulência. $\mathrm{O}$ PVC foi o material utilizado na maioria dos componentes e tubulações; a temperatura durante o processamento fotoeletroquímico foi controlada em $30^{\circ} \mathrm{C}$ e a vazão de recirculação dos 20 litros de solução foi de 2500 L.h.' .

A incidência da radiação UV na superfície do anodo foi feita a partir de uma lâmpada de vapor de mercúrio Osram HQL de $400 \mathrm{~W}$, fluência de $99,5 \mathrm{~W} \mathrm{~m}^{-2}$, a uma distância de $20 \mathrm{~cm}$. Para a inserção da lâmpada no interior do tubo de quartzo do reator, a sua cobertura original foi removida.

Os experimentos foram realizados com a aplicação de uma corrente constante de $26,5 \mathrm{~mA} . \mathrm{cm}^{-2}$, valor abaixo daquele utilizado para a otimização de um reator para a oxidação de uma solução sintética de fenol ${ }^{34}$. Durante os experimentos com o efluente E1 e com a solução de corante, a diferença de potencial entre os eletrodos permaneceu em 3,5 V. Com o chorume de lixo esse valor subiu para $5 \mathrm{~V}$.

A descoloração do efluente E1 foi determinada através de medições de absorbância em espectrofotômetro de UV-Vis, usando comprimento de onda de $465 \mathrm{~nm}$. Para o efluente da indústria têxtil e para o chorume de lixo usou-se $600 \mathrm{~nm}$ e $350 \mathrm{~nm}$, respectivamente. Esses valores correspondem àqueles comprimentos de onda para os quais observou-se a maior absorbância. Ainda para o E1, a medida de fenóis totais foi feita por UV-Vis usando o reagente de FolinCiocalteau a $700 \mathrm{~nm}$. A determinação do carbono organicamente ligado, ou carbono orgânico total (COT) foi feita no equipamento Shimadzu TOC-5000 APC. A concentração de organoclorados foi monitorada através da medida de organohalogenados absorvíveis (OXA). Para este ensaio foi utilizado o equipamento Scan-W 9-89. A medida da DQO foi realizada pela técnica tradicional onde o oxigênio equivalente da matéria orgânica é oxidado pelos íons crômio (VI) em meio ácido, na presença de um catalisador de sulfato de prata. O resultado é expresso mediante concentração em massa de oxigênio consumido na oxidação da matéria orgânica.

\section{RESULTADOS E DISCUSSÃO}

\section{Efluente da indústria de papel e celulose}

A Figura 4 mostra a evolução da cor do efluente papeleiro durante o tempo de processamento fotoeletroquímico. Como todo tratamento eletroquímico, a degradação é mais rápida no início do processo, onde a primeira hora foi suficiente para a redução de $50 \%$ da coloração inicial, significando uma redução da absorbância inicial de 0,71 para 0,35 . Nas três horas seguintes de tratamento foi possível atingir $70 \%$ de redução da cor inicial. Para avaliar a importância desse resultado, o tratamento biológico, em condições anaeróbias, acentua a cor inicial após a degradação da carga orgânica ${ }^{4}$.

Além dos compostos responsáveis pela forte coloração terem sido oxidados, observou-se também uma redução na matéria orgânica como um todo. A Figura 5 mostra a evolução da concentração das espécies fenólicas, medida como fenóis totais. A redução de $80 \%$ desses compostos foi observada na primeira hora de tratamento, evidenciando a grande capacidade do processo fotoeletroquímico para a abertura dos anéis benzênicos. Essa facilidade para degradação, que já havia sido observada antes em escala de laboratório ${ }^{22}$, foi acompanhada por uma significativa mineralização de compostos orgânicos. A Figura 5 mostra também a medida do carbono orgânico total ao longo do tempo de tratamento onde $35 \%$ do valor inicial foi reduzido. Esse valor para um efluente de alta carga orgânica (COT = $1275 \mathrm{mg} \mathrm{L}^{-1}$ ) é um bom resultado levando-se em conta o reduzido tempo de tratamento. Em geral, o tratamento convencional com lodo ativado, considerado o mais versátil e eficiente processo biológico, consegue reduzir de 10 a $30 \%$ da matéria orgânica presente em um efluente da mesma origem em 20 dias de tratamento ${ }^{35}$.

As outras características físico-químicas também apresentaram redução substancial em relação aos valores iniciais. A Tabela 4 mostra os valores de DQO, com redução maior que $50 \%$ e de AOX na mesma proporção.

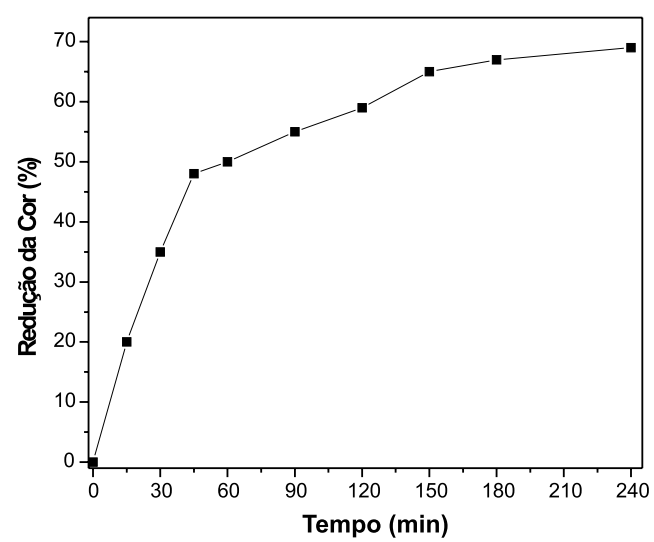

Figura 4. Redução da cor do efluente da 1ª Extração Alcalina (Kraft E1) através do tratamento fotoeletroquímico. Volume tratado 20 Litros, densidade de corrente: $26,5 \mathrm{~mA} . \mathrm{cm}^{-2}$, potência da lâmpada $400 \mathrm{~W}$, área do anodo: 1500 $\mathrm{cm}^{2}$
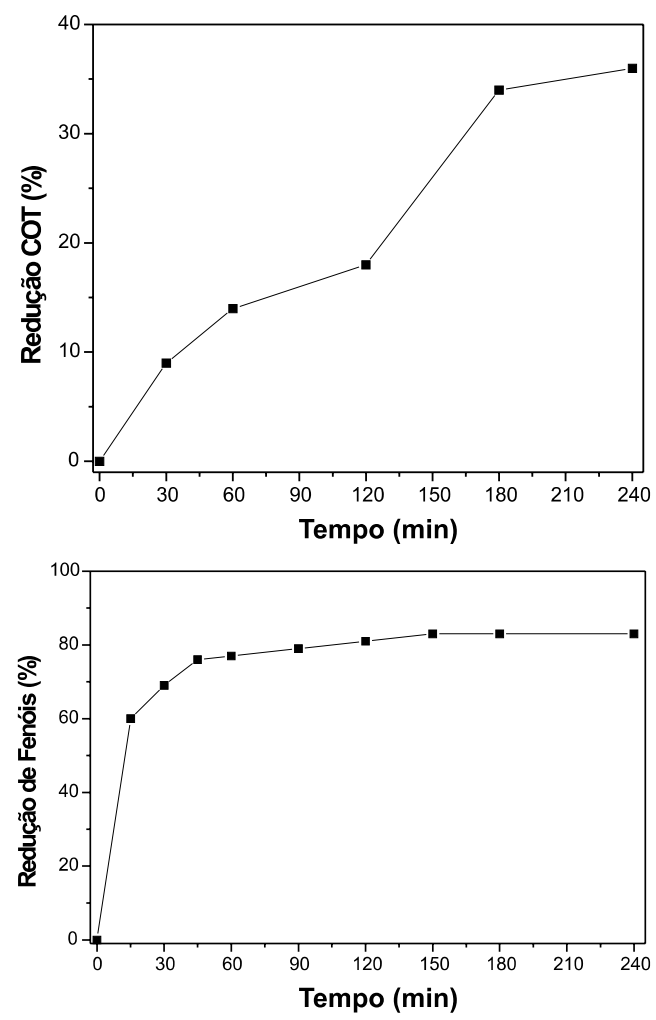

Figura 5. Reduções do teor de carbono orgânico total (COT) e da concentração de fenóis totais do efluente da 1ª Extração Alcalina (Kraft E1), através do tratamento fotoeletroquímico. Dados operacionais da Figura 4 
Tabela 4. Reduções observadas nos valores de DQO e OXA durante o tratamento fotoeletroquímico do efluente $\mathrm{E}_{1}$. Dados operacionais da Figura 4

\begin{tabular}{cccc}
\hline Tempo de tratamento $(\mathrm{h})$ & 0 & 1 & 4 \\
\hline DQO $\left(\mathrm{mg} \mathrm{L}^{-1}\right)$ & 2400 & 1950 & 1054 \\
OXA $\left(\mathrm{mg} \mathrm{L}^{-1}\right)$ & 63,4 & 57,4 & 36,1 \\
\hline
\end{tabular}

O conjunto dos resultados obtidos faz crer que o tratamento fotoeletroquímico pode ser utilizado, senão como tratamento único para o efluente papeleiro, como um pré-tratamento que antecede a digestão biológica. A expressiva facilidade em degradar as substâncias fenólicas indica a transformação dos compostos presentes no efluente em substâncias mais facilmente biodegradáveis. Esse fato, somado à redução dos outros parâmetros físico-químicos, pode propiciar eficiência maior e uma cinética mais rápida aos tratamentos biológicos.

\section{Efluente simulado da indústria têxtil}

A Figura 6 apresenta a evolução dos valores de absorbância durante o tratamento fotoeletroquímico da solução com $15 \mathrm{mg} . \mathrm{L}^{-1}$ do corante reativo Azul QR. É interessante observar que a degradação da cor já era significativa após 40 minutos de processamento. Nesse período, o valor de absorbância foi reduzido em $75 \%$. Em uma hora de tratamento, quase $90 \%$ do corante havia sido degradado.

A descoloração do corante Azul QR, conseguida com o tratamento fotoeletroquímico, foi comparada a um padrão permitido definido pela literatura ${ }^{31}$, que pode ser usado para controlar a eficiência tratamento de efluentes da indústria têxtil. A Figura 7 mostra que, a partir de 50 min de tratamento a coloração do corante, medida em vários comprimentos de ondas, encontrava-se abaixo dos padrões exigido para descarte. Esse resultado é importante porque os corantes sintéticos, em sua maioria, apresentam propriedades xenobióticas, ou seja, os sistemas naturais de microorganismos em rios e lagos não contêm enzimas específicas para degradação deste tipo de composto sob condições aeróbias, e sob condições anaeróbias a degradação do corante se processa muito lentamente ${ }^{31}$. A degradação do corante

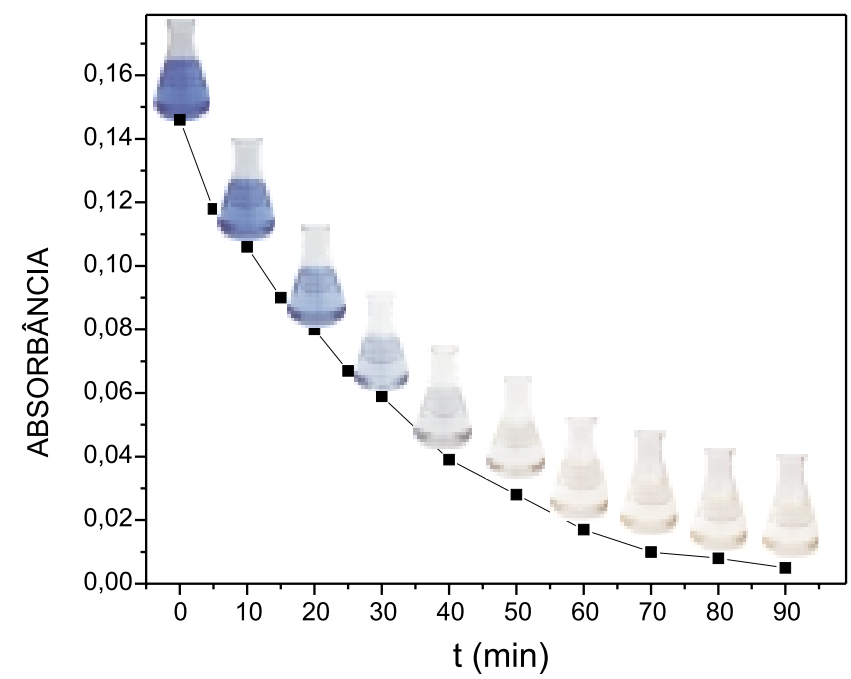

Figura 6. Redução da coloração do corante Reativo Azul QR (medido em $600 \mathrm{~nm}$ ) tratado pelo processo fotoeletroquímico. Volume tratado $20 \mathrm{~L}$, densidade de corrente de $26,5 \mathrm{~mA} . \mathrm{cm}^{-2}$, lâmpada de $400 \mathrm{~W}$, área do anodo: $1500 \mathrm{~cm}^{2}$ também foi acompanhada por uma redução no valor inicial de carbono orgânico total em $25 \%$. Na solução sintética, o valor de COT foi reduzido de $6,0 \mathrm{mg} \mathrm{L}^{-1}$ para $4,5 \mathrm{mg} \mathrm{L}^{-1}$.

Considerando que grande parte dos efluentes da indústria têxtil é composta de corantes e amido, sendo este facilmente biodegradável, o tratamento fotoeletroquímico poderia ser usado nesse caso como etapa posterior ao tratamento biológico, apenas para a remoção da cor.

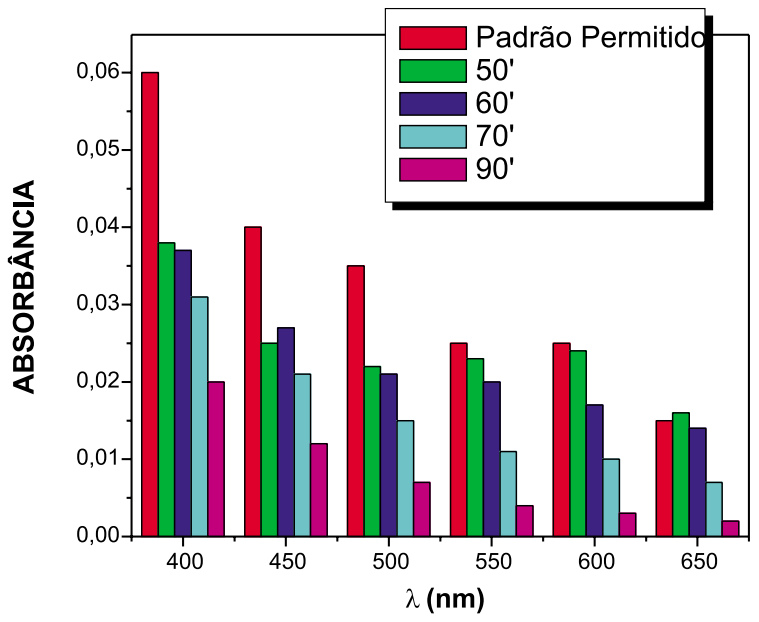

Figura 7. Análise espectrofotométrica da degradação do Corante Reativo Azul 19, comparada a um padrão definido, após tratamento fotoeletroquímico. Tempos de tratamento: 50; 60; 70 e 90 min. Dados operacionais da Figura 6

\section{Chorume de lixo doméstico}

A Figura 8 mostra a percentagem de redução de cor de uma amostra de chorume através do tratamento fotoeletroquímico e, para melhor visualização, a curva está acompanhada da fotografia das amostras colhidas ao longo do experimento. É possível observar redução de cor de $75 \%$ a partir de 5 horas de tratamento, embora 2 horas tivessem sido suficiente para a redução de $60 \%$. Em se tratan-

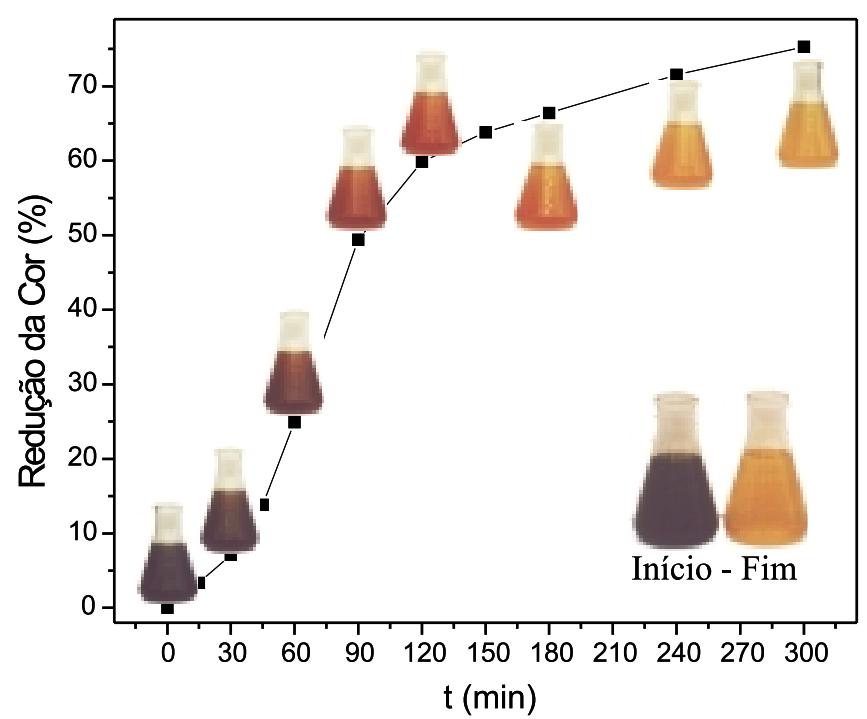

Figura 8. Redução da cor do chorume (medido em $350 \mathrm{~nm}$ ) através do tratamento fotoeletroquímico. Volume tratado $20 \mathrm{~L}$, densidade de corrente de 26,5 $\mathrm{mA} \mathrm{cm}^{-2}$, lâmpada de $400 \mathrm{~W}$, área do anodo: $1500 \mathrm{~cm}^{2}$ 
do de chorume de lixo, de coloração negra, esse grau de descoloração pode viabilizar um tratamento biológico posterior com maior eficiência e cinética mais rápida.

A descoloração também foi acompanhada de uma redução da carga orgânica em 20\%. O valor do carbono orgânico total foi reduzido em $600 \mathrm{mg} \mathrm{L}^{-1}$ (vide valor inicial na Tabela 3), que traduz a fração mineralizada do carbono organicamente ligado. Como informação adicional, o odor característico do chorume desapareceu por completo a partir da terceira hora de processamento.

\section{CONCLUSÕES}

O processo fotoeletroquímico para tratamento de poluentes químicos representa uma nova concepção em tratamento de rejeitos aquosos. Os resultados conseguidos com a aplicação desta técnica indicam que esta metodologia é eficiente para tratar compostos poluentes de caráter recalcitrantes e efluentes com amplo espectro de poluentes químicos. Em todos os experimentos o processo fotoeletroquímico apresentou boa performance para tratar soluções com forte coloração. Diante dos resultados alcançados, o processo fotoeletroquímico apresenta-se como uma técnica com real possibilidade de aplicação em grande escala, podendo também ser empregada como pré-tratamento e contribuir de maneira acentuada para a biodegradabilidade dos compostos recalcitrantes.

\section{REFERÊNCIAS}

1. Buitrón, G.; Gonzáles, A.; Wat. Sci. Tech. 1996, 34, 289.

2. Mohn, W. W.; Martin, V. J. J. E.; Yu, Z. T.; Wat. Sci. Tech. 1999, 40, 273.

3. Archibald, F. S.; Valeanu L.; Leichtle G.; Guilbault, B.; Water Qual. Res. J. 1998, 33, 347.

4. Garg, S.K.; Modi, D. R.; Crit. Rev. Biotech. 1999, 19, 85.

5. Hodgson, A.; Sheldon, J. B.; Alan, J. H.; Stevenson, B.; Environ. Conf. 1997, 1, 307.

6. Kapdan, I.K; Kargi, F.; McMullan, G.; Marchant, R.; Environ. Technol. 2000, 21, 236

7. Kirby, N.; Marchant, R.; Mc Mullan, G.; FEMS Microbiol. Lett. 2000, 188, 93.
8. Knapp, J. S.; Zhang, F.; Tapley, K.; J. Chem. Technol. Biotechnol. 1997, $69,289$.

9. Alabaster, G. P.; Mills, S. W.; Osebe, A. S.; Thitai, W. N.; Pearson, H. W.; Mara, D. D.; Muiruri, P.; Wat. Sci. Tech. 1991, 24, 43.

10. Comninellis, Ch; Plattner, E.; Chimia 1988, 42, 250.

11. Comninellis, Ch; Pulgarin, C.; J. Appl. Electrochem. 1991, 21, 703.

12. Comninellis, Ch; Gas, Wasser, Abwasser 1992, 11, 792.

13. Comninellis, Ch; Pulgarin, C.; J. Appl. Electrochem. 1993, 23, 108.

14. Comninellis, Ch. Em Environmental Oriented Electrochemistry C.A.C Sequeira (Ed.), Elsevier, Amsterdam, 1994, p. 77.

15. Comninellis, Ch.; Electrochim. Acta 1994, 39, 1857.

16. Savall, A.; Chimia 1995, 49, 23.

17. Fóti, G.; Gandini, D.; Comninellis, Ch; Curr. Top. Electrochem. 1997, 5, 71.

18. Simond, O.; Schaller, V.; Comninellis, Ch.; Electrochim. Acta 1997, 42, 2009.

19. Correa-Lozano, B.; Comninellis, Ch.; De Battisti, A.; J. Appl. Electrochem. 1997, 27, 970.

20. Pelegrini, R.; Peralta-Zamora, P; Andrade, A. R.; Reyes, J.; Duran, N; Appl. Catal., B 1999, 22, 83.

21. Pelegrini, R.; Reyes, J.; Duran, N.; Peralta-Zamora, P; Andrade, A. R.; J. Appl. Electrochem. 2000, 30, 953.

22. Pelegrini, R.; Freire, R. S.; Duran, N.; Bertazzoli, R.; Environ. Sci. Technol. 2001, 35, 2849.

23. Pelegrini, R.; Bertazzoli, R; Patentes Brasileiras, PI2455-4, 2000; PI49891, 2000; PI4988-3, 2000; PI4987-5, 2000; PI4986-7, 2000.

24. Ziolli, R. L.; Jardim, W. F.; Quim. Nova 1998, 21, 319.

25. Suominen, K. P.; Wittmann, C; Liukkonen, M.; Kahkonen, M. A.;SalkinojaSalonen, M. S.; Environ. Tox. Chem. 1999, 18, 2262.

26. Sant'Anna, G. L.; Proc. 2nd Braz. Symp. Chem. Lignins and Other Wood Comp. Belo Horizonte, Brasil, 1992, 3, 297.

27. Reid, I. D.; Appl. Environ. Microbiol. 1998, 64, 2117.

28. Rintala, J.; Lepisto, R.; Chand, S.; Bioresour. Technol. 1992, $42,17$.

29. Hart, P. W.; Hsieh, J. S.; Tappi J. 1991, 74, 117.

30. Durán N.; Dezotti, M.; Rodriguez, J.; J. Photochem. Photobiol., A 1991, 62, 269.

31. Guaratini, C. C. I.; Zanoni, M. V. B.; Quim. Nova 2000, 23, 71.

32. Pierce, J.; Towards Cleaner Environ. 1994, 110, 131.

33. Ince N. H.; Water Environ. Res. 1998, 70, 1161.

34. Pelegrino, R. R. L.; Di Iglia, R. A.; Sanches, C.G.; Avaca, L. A.; Bertazzoli, R.; J. Braz. Chem. Soc. 2002, 13, 60.

35. Cecen, F.; Wat. Sci. Tech. 1999, 40, 305. 